\title{
Characteristics of Office-Based Buprenorphine Prescribers for Medicare Patients
}

\author{
Rohit Abraham, MD, MPH, MAT, Elizabeth Wilkinson, BA, Yalda Jabbarpour, MD, \\ Stephen Petterson, PhD, and Andrew Bazemore, MD
}

Introduction: Opioid use disorder (OUD) is a major and growing public health concern, and Medicare patients have nearly double the proportion of OUD prevalence compared with those with commercial insurance. This study examines provider-level characteristics to delineate the wide variation behind buprenorphine provision, which is the mainstay of medication-assisted treatment for OUD.

Methods: Using Medicare Part D Public Use Files claims data from 2013 to 2016 in all states, we assessed prescribing patterns of buprenorphine formulations for the specialties of family medicine, internal medicine, psychiatry, and general practice. We incorporated data from 2013 to 2016 American Medical Association Physician Masterfile to model various provider- and area-level characteristics as predictors of buprenorphine prescriber status.

Results: Family medicine and internal medicine comprise nearly two-thirds of the outpatient buprenorphine prescriber population for Medicare beneficiaries. Yet, both specialties also have the lowest proportion of active buprenorphine prescribers compared with psychiatrists and general practitioners. Additional characteristics associated with buprenorphine provision include male sex, osteopathic training, Northeast region, US undergraduate medical education, more years in practice, and a higher proportion of dual-eligible patients.

Conclusions: Primary care specialties, such as family medicine and internal medicine, currently comprise a significant majority of the US buprenorphine prescriber population for Medicare beneficiaries. Future policies should target specific demographics to enable greater patient access from physicians who are characteristically less likely to prescribe buprenorphine to increase overall capacity. (J Am Board Fam Med 2020;33:9-16.)

Keywords: American Medical Association, Buprenorphine, Medicare Part D, Opioid-Related Disorders, Primary Health Care, Public Health

The growing opioid epidemic has long been declared a national public health emergency, with nearly 1 million deaths attributable to opioid use disorder (OUD) since the turn of the century. ${ }^{1}$ Medications for OUD (MOUD) are well established as the standard of care in OUD management and are associated with reduced rates of illicit drug

This article was externally peer reviewed.

Submitted 27 June 2019; revised 30 September 2019; accepted 6 October 2019.

From Boston University School of Medicine, Departments of Family Medicine and Psychiatry, Boston, MA (RA); Robert Graham Center for Policy Studies in Family Medicine and Primary Care, Washington, DC (EW, YJ, SP, AB).

Funding: none.

Conflict of interest: none declared.

Corresponding author: Rohit Abraham, MD, MPH, MAT, Boston University School of Medicine, Boston, MA 02118 (E-mail: rohit.abraham@bmc.org). use, overdoses, infectious disease transmission, and crime. $^{2-5}$ Of the Food and Drug Administration (FDA)-approved MOUD options, buprenorphine has demonstrated the largest potential to increase continuous patient access safely through officebased therapy (OBT). ${ }^{6-8}$ Physicians have long been required by FDA policy to undergo an 8-hour training to obtain a DATA-2000 waiver to prescribe buprenorphine-containing medications. ${ }^{9}$ In the past couple of years, nurse practitioners and physician assistants have also been approved for waiver training under a new policy.

Despite innovative initiatives to begin buprenorphine inductions in hospital and emergency department settings, ${ }^{10,11}$ a widespread provision has been most limited by a bottleneck in the primary care workforce capacity. Although psychiatry is typically 
regarded as the specialty with the most extensive OUD training, primary care specialties may have a greater role in bridging access gaps, particularly in rural and urban underserved communities established as health professional shortage areas. ${ }^{12-14}$

Little is known about provider-level characteristics for outpatient buprenorphine provision reimbursed by any payer model. ${ }^{15}$ Although nurse practitioners and physician assistants can also now become DATA-2000 waivered, most states still require physician oversight, especially with controlled substances. Previous studies suggest higher buprenorphine provision in urban and coastal counties, particularly in the Northeast. ${ }^{15,16}$ To our knowledge, the existing literature has not explored this provider population by specialty within Medicare, which accounted for nearly double the diagnosed OUD prevalence compared with commercial payers in $2015 .{ }^{17}$ Our objective was to describe the physician-level characteristics of the population of buprenorphine prescribers who treat Medicare beneficiaries.

\section{Methods}

We conducted a repeated cross-sectional study of Medicare Part D claims data for descriptive and regression analysis of specialty trends in buprenorphine provision. A list of buprenorphine-containing medications, validated by a board-certified addiction medicine specialist, is compiled in the Appendix.

\section{Data Sources}

This study includes prescribers in Medicare Part D Prescriber Public Use Files from 2013 to 2016 in all states and the District of Columbia. We combined Medicare Part D Prescriber Public Use Files with 2013 to 2016 Medicare Part D Provider Summary Public Use Files to obtain provider and patient panel characteristics. We further supplemented these data with information from the 2013 to 2016 American Medical Association Physician Masterfile to identify practice location, training, and other demographic trends. We used 2013 to 2016 Medicare Physician and Other Supplier Public Use File to identify physicians working as hospitalists. At the time of this study, we were unable to obtain DATA-2000 waiver rosters from the Drug Enforcement Agency or from the Substance Abuse and Mental Health Services Administra- tion's Center for Substance Abuse Treatment to cross-reference physician waiver status.

\section{Variables}

We used the 2013 to 2016 American Medical Association Physician Masterfile to assess physician characteristics, including self-reported specialty, practice location by census region, age, sex, allopathic or osteopathic training, international or domestic medical school, and years in practice. We assessed patient panel characteristics from the Medicare Part D Provider Summary Public Use Files, including Medicare patient panel size, the proportion of a provider's patients with dualeligible beneficiary status with Medicare and Medicaid, and patient's average hierarchical condition category risk score. In cases where data on the race of patients were redacted, we imputed the share of patients who are white by using the difference between the total number of patients and the sum of patients of nonwhite races.

We limited included specialties by volume to the top 4 outpatient buprenorphine prescriber groups-family medicine, internal medicine, psychiatry, and general practice. Due to limited sensitivity of the Medicare Part D Public Use File claims database, physicians were only included if they billed for 11 or more instances of any prescription. We excluded any physician with more than $90 \%$ of annual claims from hospital-based settings for accurate capture of the OBT workforce. We also excluded physicians with fewer than 30 Medicare beneficiaries to mitigate bias of other missing information.

\section{Statistical Analysis}

We used STATA version 14 for all statistical analysis. Descriptive analysis characterized buprenorphine prescriber versus nonprescriber populations by various demographic factors. We then performed multivariate logistic regression analysis on nonpsychiatry primary care specialties to use provider-level factors as predictors of buprenorphine prescriber status, while adjusting for patient panel characteristics—sex, dual-eligible beneficiary status, and overall health status, as measured by hierarchical condition category risk score. Compared with the provider's full Medicare panel, the shares of white patients and dual-eligible beneficiaries were reported above and below the sample mean. The exclusion of psychiatry in this model was to 
Figure 1. Percent of Buprenorphine prescribers within Specialty for medicare beneficiaries, 2013-2016.

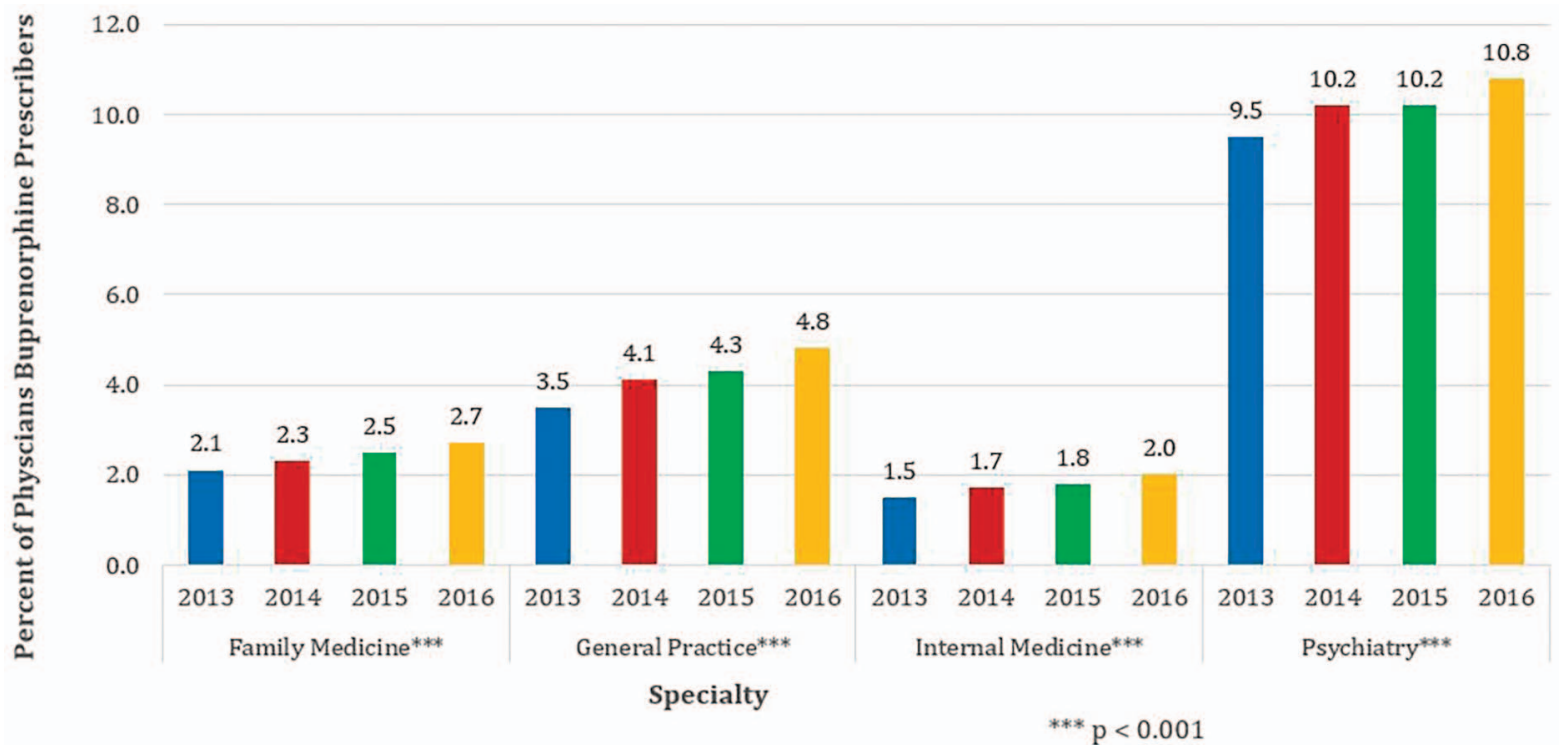

delineate the variation specific to primary care fields, which make up the majority of the OBT workforce population for Medicare beneficiaries.

\section{Results}

Our sample included 597,975 physicians pooled across the 4 sample years (2013 to 2016) that were buprenorphine prescribers to the Medicare population (Table 1). Of these, 287,393 were family physicians, 242,146 were general internists, 16,184 were general practitioners, and 52,252 were psychi- atrists. Within each specialty, we found wide variation in the overall percentage of buprenorphine prescribers. In 2016, psychiatry held the highest proportion of such buprenorphine prescribers at $10.8 \%$, with general practice, family medicine, and internal medicine following at $4.8 \%, 2.7 \%$, and $2.0 \%$, respectively (Figure 1). All 4 specialties experienced slight increases across the study period at roughly equivalent rates.

However, an examination of workforce composition across specialties—as opposed to within each

Figure 2. Share of Buprenorphine prescribers by Specialty for medicare beneficiaries, 2013-2016.

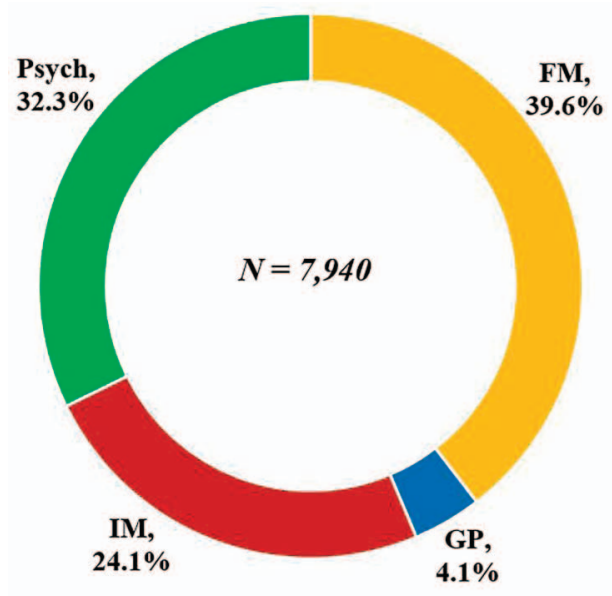

2013-2014

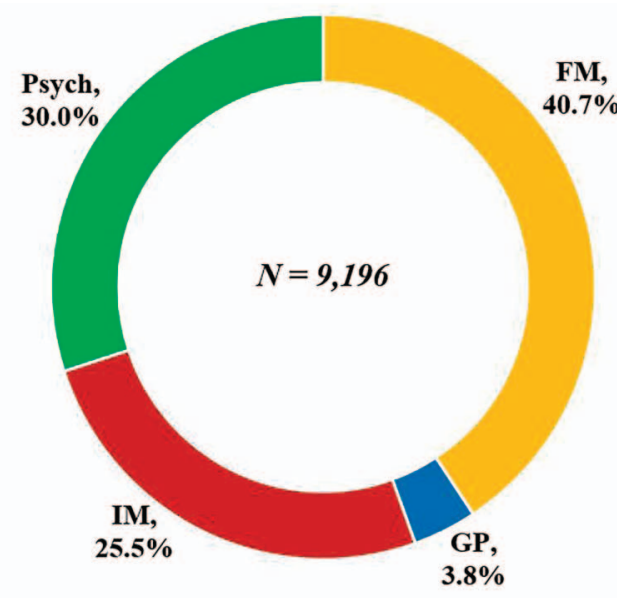

2015-2016 
Table 1. Characteristics of Medicare Part D Outpatient Providers by Prescriber Status, 2013 to 2016

\begin{tabular}{|c|c|c|c|}
\hline Characteristic & $\begin{array}{c}\text { Prescribers of } \\
\text { Buprenorphine, \# (\%) }\end{array}$ & $\begin{array}{c}\text { Non-Prescribers of } \\
\text { Buprenorphine, \# (\%) }\end{array}$ & $\begin{array}{l}\text { Total Primary Care } \\
\text { Providers, \# (100\%) }\end{array}$ \\
\hline Total & $11,818(2.2)$ & $533,905(97.8)$ & 545,723 \\
\hline \multicolumn{4}{|l|}{ Specialty } \\
\hline Family Practice & $6,891(2.4)$ & $280,502(97.6)$ & 287,393 \\
\hline Internal Medicine & $4,255(1.8)$ & $237,891(98.2)$ & 242,146 \\
\hline General Practice & $672(4.2)$ & $15,512(95.8)$ & 16,184 \\
\hline \multicolumn{4}{|l|}{ Gender } \\
\hline Male & $9,177(2.6)$ & $339,010(97.4)$ & 348,187 \\
\hline Female & $2,641(1.3)$ & $194,895(98.7)$ & 197,536 \\
\hline \multicolumn{4}{|l|}{ Degree Type } \\
\hline Allopath & $9,684(2.0)$ & $466,682(98.0)$ & 476,366 \\
\hline Osteopath & $2,134(3.1)$ & $67,223(96.9)$ & 69,357 \\
\hline \multicolumn{4}{|l|}{ Medical School Type } \\
\hline USMG & $10,414(2.2)$ & $467,959(97.8)$ & 478,373 \\
\hline IMG & $1,404(2.1)$ & $65,946(97.9)$ & 67,350 \\
\hline \multicolumn{4}{|l|}{ Region } \\
\hline Northeast & $4,032(3.7)$ & $103,550(96.3)$ & 107,582 \\
\hline Midwest & $2,007(1.6)$ & $121,093(98.4)$ & 123,100 \\
\hline South & $3,809(2.1)$ & $180,015(97.9)$ & 183,824 \\
\hline West & $1,970(1.5)$ & $129,247(98.5)$ & 131,217 \\
\hline \multicolumn{4}{|l|}{ Rurality } \\
\hline Urban & $10,091(2.1)$ & $470,514(97.9)$ & 480,605 \\
\hline Rural & $1,727(2.7)$ & 63,391 (97.3) & 65,118 \\
\hline \multicolumn{4}{|l|}{ Years Since Medical School } \\
\hline$<10$ & $732(1.4)$ & $52,822(98.6)$ & 53,554 \\
\hline 10 to 14 & $1,164(1.8)$ & $65,225(98.2)$ & 66,389 \\
\hline 15 to 19 & $1,653(1.9)$ & $85,603(98.1)$ & 87,256 \\
\hline 20 to 29 & $3,561(2.3)$ & $154,105(97.7)$ & 157,666 \\
\hline $30+$ & $4,708(2.6)$ & $176,150(97.4)$ & 180,858 \\
\hline \multicolumn{4}{|l|}{ Number of Medicare Patients } \\
\hline 30 to 50 & $643(3.1)$ & $19,956(96.9)$ & 20,599 \\
\hline 50 to 200 & $4,027(2.3)$ & $170,394(97.7)$ & 174,421 \\
\hline 200 to 500 & $5,274(2.1)$ & $246,462(97.9)$ & 251,736 \\
\hline$>500$ & $1,874(1.9)$ & $97,093(98.1)$ & 98,967 \\
\hline \multicolumn{4}{|c|}{ Share of Medicare Patients who are Dual Eligible } \\
\hline$<35 \%$ of Patients Dual Eligible & $4,707(1.3)$ & $357,495(98.7)$ & 362,202 \\
\hline $35+\%$ of Patients Dual Eligible & $7,111(3.9)$ & $176,410(96.1)$ & 183,521 \\
\hline \multicolumn{4}{|c|}{ Share of Medicare Patients who are White } \\
\hline$<75 \%$ of Patients White & $3,927(2.1)$ & $181,786(97.9)$ & 185,713 \\
\hline $75 \%+$ of Patients White & $7,891(2.2)$ & $352,119(97.8)$ & 360,010 \\
\hline \multicolumn{4}{|c|}{ Medicare Beneficiary Average HCC Risk Score } \\
\hline $0.442-1.0551$ & $1,942(1.3)$ & $141,964(98.7)$ & 143,906 \\
\hline $1.0552-1.2043$ & $2,743(2.0)$ & $134,335(98.0)$ & 137,078 \\
\hline $1.2044-1.4128$ & $3,576(2.8)$ & $125,077(97.2)$ & 128,653 \\
\hline $1.4129-9.1466$ & $3,557(2.6)$ & $132,529(97.4)$ & 136,086 \\
\hline
\end{tabular}

IMG, International Medical School Graduate; USMG, US Medical School Graduate; HCC, Hierarchical Condition Category.

specialty—revealed instead that family medicine and internal medicine comprise a significant majority of outpatient buprenorphine prescribers. In 2016, two-thirds $(66.6 \%)$ of the entire OBT bu- prenorphine prescriber population were physicians in family medicine and internal medicine. These proportions also did not change appreciably during the study period: family medicine, internal medi- 
Table 2. Multivariate Logistic Regression Results for Odds of Buprenorphine Prescriber Status Based on 2013 to 2016 Medicare Part D Public Use File Data

\begin{tabular}{|c|c|c|}
\hline & Odds Ratio & (Standard Error) \\
\hline \multicolumn{3}{|l|}{ Specialty } \\
\hline Family Medicine & REF & \\
\hline Internal Medicine & $0.689^{* * *}$ & $(0.0263)$ \\
\hline General Practice & $1.265^{\text {*** }}$ & $(0.0953)$ \\
\hline \multicolumn{3}{|l|}{ Gender } \\
\hline Male & REF & \\
\hline Female & $0.512^{* * *}$ & $(0.0208)$ \\
\hline \multicolumn{3}{|l|}{ Degree Type } \\
\hline Allopathic & REF & \\
\hline Osteopathic & $1.341^{* * *}$ & $(0.0619)$ \\
\hline \multicolumn{3}{|l|}{ Rurality } \\
\hline Urban & REF & \\
\hline Rural & 0.968 & $(0.0482)$ \\
\hline \multicolumn{3}{|l|}{ Region } \\
\hline Northeast & REF & \\
\hline Midwest & $0.442^{* * *}$ & $(0.0227)$ \\
\hline South & $0.550^{* * *}$ & $(0.0239)$ \\
\hline West & $0.437^{* * *}$ & $(0.0221)$ \\
\hline \multicolumn{3}{|l|}{ Medical School Type } \\
\hline Domestic & REF & \\
\hline International & $0.818^{* * *}$ & $(0.0436)$ \\
\hline \multicolumn{3}{|l|}{ Years Since Medical School } \\
\hline$<10$ & REF & \\
\hline 10 to 14 & $1.420^{* * *}$ & $(0.0958)$ \\
\hline 15 to 19 & $1.602^{* * *}$ & $(0.108)$ \\
\hline 20 to 29 & $1.890^{* * *}$ & $(0.120)$ \\
\hline $30+$ & $1.935^{* * *}$ & $(0.123)$ \\
\hline \multicolumn{3}{|l|}{ Number of Medicare Patients } \\
\hline 30 to 50 & REF & \\
\hline 50 to 200 & $0.846^{* * *}$ & $(0.0506)$ \\
\hline 200 to 500 & $0.790^{* * *}$ & $(0.0487)$ \\
\hline$>500$ & $0.678^{* * *}$ & $(0.0476)$ \\
\hline \multicolumn{3}{|c|}{ Medicare Beneficiary Average HCC Risk Score } \\
\hline $0.4420-1.0551$ & REF & \\
\hline $1.0552-1.2043$ & $1.274^{* * *}$ & $(0.0516)$ \\
\hline $1.2044-1.4128$ & $1.486^{* * *}$ & $(0.0682)$ \\
\hline $1.4129-9.1466$ & $1.165^{* * *}$ & $(0.0585)$ \\
\hline \multicolumn{3}{|c|}{ Share of Patients who are Dual Eligible } \\
\hline$<35 \%$ Patients Dual Eligible & REF & \\
\hline$>35 \%$ Patients Dual Eligible & $3.518^{* * *}$ & $(0.139)$ \\
\hline \multicolumn{3}{|c|}{ Share of Patients who are White } \\
\hline$<75 \%$ Patients White & REF & \\
\hline$>75 \%$ Patients White & $1.622^{* * *}$ & $(0.0640)$ \\
\hline \multicolumn{3}{|l|}{ Year } \\
\hline 2013 & REF & \\
\hline 2014 & $1.141^{* * *}$ & $(0.0149)$ \\
\hline
\end{tabular}

Continued
Table 2. Continued

\begin{tabular}{lcc}
\hline & Odds Ratio & (Standard Error) \\
\hline 2015 & $1.227^{* * *}$ & $(0.0199)$ \\
2016 & $1.368^{* * *}$ & $(0.0245)$ \\
Constant & $0.0106^{* * *}$ & $(0.00109)$ \\
Observations & 545,723 & \\
\hline
\end{tabular}

${ }^{* * *} P<.01,{ }^{* *} P<.05,{ }^{*} P<.1$.

USMG, US Medical School Graduate; IMG, International Medical School Graduate, HCC, Hierarchical Condition Category; REF, "reference" point for the odds ratio comparisons within the regression model.

cine, psychiatry, and general practice comprised $40.7 \%, 25.5 \%, 30.0 \%$, and $3.8 \%$ of the OBT prescriber workforce, respectively, from 2015 to 2016 (Figure 2). Notably, this lackluster change represents an important negative finding in a time period when many political resources and attention were being focused on treatment expansion for the opioid crisis.

Besides specialty, we noted statistically significant differences in nonpsychiatry provider demographics between prescribers and nonprescribers (Table 2). Primary care specialists were more likely to prescribe buprenorphine based on the following factors: increasing year as the study period went on, increased years out of residency, decreasing size of Medicare patient panel, and decreased white patient panel. The only nonsignificant finding was rurality.

\section{Discussion}

Well over a decade after DATA-2000 waivers were approved by Congress, buprenorphine provision continues to be woefully underutilized in OUD management. The present study found that family medicine and internal medicine comprise nearly two-thirds of the US OBT prescriber population, aligning with the relative proportions found by a national program director survey across these specialties. ${ }^{18}$ Yet, when we examined the proportion of each specialty that prescribes to the Medicare population, psychiatry boasted the highest within-specialty proportion of buprenorphine provision, with $10.8 \%$ of psychiatrists providing buprenorphine as opposed to only $2.7 \%$ of family physicians and $2.0 \%$ of general internists. This suggests that primary care specialists have more room for prescribing growth than previously estimated through a physician survey of buprenorphine provision..$^{9,20}$ 
Populations of primary care physicians who are less likely to be buprenorphine prescribers for Medicare patients are those with fewer years out of residency, those who are female physicians, those who practice in regions outside the Northeast, those with foreign medical training, those with larger panels of Medicare beneficiaries, those with smaller panels of dual-eligible beneficiaries, and those with larger panels of nonwhite patients. By targeting these demographics, future studies may identify specific interventions that increase OBT buprenorphine prescribing rates among such physician subgroups. ${ }^{17}$

Our study had several important limitations that are inherent to its design. First, our retrospective claims data limit causal interpretation for our findings. To overcome the limited sensitivity of Medicare Part D Public Use File database, we required 11 or more claims for inclusion. Second, we were unable to access diagnosis codes to delineate non-OUD indications, such as chronic pain. However, we attempted to mitigate this limitation by intentional exclusion of buprenorphine-containing formulations specific to pain management. Third, not all the medications that met our inclusion criteria are covered by Medicare; although, this should not cause a directional bias toward any particular specialty. Fourth, additional selection bias is introduced because some OBT prescribers avoid Medicare altogether through cash-only provision. Finally, approximately $28 \%$ Medicare beneficiaries do not receive Part $\mathrm{D},{ }^{21}$ resulting in an inability for our study to capture this subpopulation, which may potentially have a higher incidence of OUD. As mentioned in the introduction, we believe the current findings to be significant to policy makers given that the Medicare population boasts double the diagnosed OUD prevalence compared with populations of commercial payers. ${ }^{17}$ However, future studies would be necessary to make the determination of whether this article's findings translate to non-Medicare populations, especially given the challenge of integrating heterogeneous claim data from private and state-dependent Medicaid payers with highly diverse beneficiary inclusion and coverage criteria.

Primary care physicians may be empowered to play a key role in addressing the gap in MOUD provision to combat the opioid crisis through policy changes in their medical education. Removing the DATA-2000 waiver barrier may help increase physician prescribing rates-yet, waivers are only a part of the story. A known step-off exists between the potential, DATA-waivered, and active pre- scriber populations; in fact, a recent study estimates that nearly a quarter of DATA-waivered physicians are not active prescribers. ${ }^{18}$ Many theories exist for why this may be happening. A recent study suggests that even after an 8-hour training, more than onethird of waivered physicians may not feel they have adequate training to prescribe these medications without an experienced physician mentor. ${ }^{17}$

Graduate and continuing medical education programs of all primary care specialties must take strategic action to expand the quantity and quality of their addiction medicine curricula. Policy efforts to include MOUD provision as a core competency that is required to graduate from residency training programs may also help curb the growing mortality rate in the national opioid crisis. Future directions will include investigating similar trends in national Medicaid claim data to further generalize characteristics of high-frequency MOUD providers along the spectrum of provision.

We thank YoonKyung Chung for help with data abstraction and conceptualization of data analysis.

To see this article online, please go to: http://jabfm.org/content/ 33/1/9.full.

\section{References}

1. Centers for Disease Control and Prevention. Understanding the epidemic. Available from: https://www. cdc.gov/drugoverdose/epidemic/index.html. Published 2018. Accessed June 23, 2019.

2. Pew Charitable Trusts. The case for medicationassisted treatment, 2017. Available from: https:// www.pewtrusts.org/en/research-and-analysis/factsheets/2017/02/the-case-for-medication-assistedtreatment. Published 2017. Accessed on June, 23, 2019.

3. Tsui JI, Evans JL, Lum PJ, Hahn JA, Page K. Association of opioid agonist therapy with lower incidence of hepatitis $\mathrm{C}$ virus infection in young adult injection drug users. JAMA Intern Med 2014;174:1974-81.

4. French MT, Zarkin GA, Hubbard RL, Rachal JV. The effects of time in drug abuse treatment and employment on posttreatment drug use and criminal activity. Am J Drug Alcohol Abuse 1993;19:19-33.

5. Merrill J, Alterman A, Cacciola J, Rutherford M. Prior treatment history and its impact on criminal recidivism. J Subst Abuse Treat 1999;17:313-9.

6. Rinaldo SG, Rinaldo DW. Availability without accessibility? State Medicaid coverage and authorization requirements for opioid dependence medications. In: Advancing Access to Addiction Medications: Implications for Opioid Addiction 
Treatment. Rockville, MD: American Society of Addition Medicine; 2013. P. 9-71.

7. Dick AW, Pacula RL, Gordon AJ, et al. Growth in buprenorphine waivers for physicians increased potential access to opioid agonist treatment, 2002-11. Health Aff (Millwood) 2015;34:1028-34.

8. Substance Abuse and Mental Health Services Administration. Practitioner and Program Data. Available from: https://www.samhsa.gov/medicationassisted-treatment/training-materials-resources/ practitioner-program-data. Published 2019. Accessed on December, 10, 2019.

9. Stein BD, Dick AW, Sorbero M, et al. A populationbased examination of trends and disparities in medication treatment for opioid use disorders among Medicaid enrollees. Subst Abus 2018;39:419-25.

10. D'Onofrio G, O'Connor PG, Pantalon MV, et al. Emergency department-initiated buprenorphine/ naloxone treatment for opioid dependence: a randomized clinical trial. JAMA 2015;313:1636-44.

11. Liebschutz JM, Crooks D, Herman D, et al. Buprenorphine treatment for hospitalized, opioid-dependent patients: a randomized clinical trial. JAMA Intern Med 2014;174:1369-76.

12. Wingrove P, Park B, Bazemore A. Rural opioid use disorder treatment depends on family physicians. Am Fam Physician, 2016;94:546.

13. Crothers J, Petterson S, Bazemore A, Wingrove P. Family medicine: an underutilized resource in addressing the opioid epidemic. Am Fam Physician, 2016;94:350.

14. Andrilla CA, Moore TE, Patterson DG. Overcoming barriers to prescribing buprenorphine for the treatment of opioid use disorder: recommenda- tions from rural physicians. J Rural Health 2019; 35:113-21.

15. Lin LA, Knudsen HK. Comparing buprenorphineprescribing physicians across nonmetropolitan and metropolitan areas in the United States. Ann Fam Med 2019;17:212-20.

16. Huhn AS, Dunn KE. Why aren't physicians prescribing more buprenorphine? J Subst Abuse Treat 2017;78, 1-7.

17. Davenport S, Matthews K. Opioid use disorder in the United States: diagnosed prevalence by payer, age, sex, and state. Milliman White Paper. Available from: http://www.milliman.com/insight/2018/Opioid-usedisorder-in-the-United-States-Diagnosed-prevalenceby-payer-age-sex-and-state/. Published 2018. Accessed on June, 23, 2019.

18. Tesema L, Marshall J, Hathaway R, Pham C, Clarke C, Bergeron G. Training in office-based opioid treatment with buprenorphine in US residency programs: a national survey of residency program directors. Subst Abus 2018;39:1-7.

19. Wen H, Borders TF, Cummings JR. Trends in buprenorphine prescribing by physician specialty. Health Aff 2019;38:24-8.

20. Parran TV, Muller JZ, Chernyak E, et al. Access to and payment for office-based buprenorphine treatment in Ohio. Subst Abus 2017;11,1-6.

21. Cubanski D, Damico A, Neuman T. Medicare Part D in 2018: the latest on enrollment, premiums, and cost sharing. Kaiser Family Foundation. Available from: https://www.kff.org/medicare/issue-brief/ medicare-part-d-in-2018-the-latest-on-enrollmentpremiums-and-cost-sharing/. Published 2018. Accessed on September, 27, 2019. 
Appendix Table A. MAT Medications indexed in Medicare Part D

\begin{tabular}{|c|c|c|c|}
\hline $\begin{array}{l}\text { Generic } \\
\text { Equivalents }\end{array}$ & $\begin{array}{c}\text { Brand } \\
\text { Equivalents }\end{array}$ & Part D (Generic Name) & Part D (Brand Name) \\
\hline \multirow{5}{*}{$\begin{array}{l}\text { Buprenorphine } \\
\mathrm{HCl}\end{array}$} & N/A & BUPRENORPHINE HCL & BUPRENORPHINE HCL \\
\hline & Buprenex & BUPRENORPHINE HCL & BUPRENEX \\
\hline & Subutex & - & - \\
\hline & Sublocade & - & - \\
\hline & Belbuca & BELBUCA & BUPRENORPHINE HCL \\
\hline $\begin{array}{l}\text { Buprenorphine } \\
\text { Transdermal }\end{array}$ & Butrans & BUPRENORPHINE & BUTRANS \\
\hline $\begin{array}{l}\text { Buprenorphine } \\
\text { Subdermal }\end{array}$ & Probuphine & N/A & N/A \\
\hline \multirow[t]{4}{*}{$\begin{array}{l}\text { Buprenophine }+ \\
\text { Naloxone }\end{array}$} & N/A & BUPRENORPHINE HCL/NALOXONE HCL & $\begin{array}{l}\text { BUPRENORPHINE- } \\
\text { NALOXONE }\end{array}$ \\
\hline & Suboxone & BUPRENORPHINE HCL/NALOXONE HCL & SUBOXONE \\
\hline & Zubsolv & BUPRENORPHINE HCL/NALOXONE HCL & ZUBSOLV \\
\hline & Bunavail & BUPRENORPHINE HCL/NALOXONE HCL & BUNAVAIL \\
\hline
\end{tabular}

Appendix Table B. Prescribers of Buprenorphine in Medicare Part D by Specialty, 2013 to 2016

\begin{tabular}{|c|c|c|c|c|c|c|c|}
\hline \multirow[b]{2}{*}{ Specialty } & \multirow{2}{*}{$\begin{array}{l}\text { Buprenorphine } \\
\text { Prescriber }\end{array}$} & \multicolumn{5}{|c|}{ Year } & \multirow[b]{2}{*}{$P$ Value } \\
\hline & & 2013 & 2014 & 2015 & 2016 & Total & \\
\hline \multirow[t]{3}{*}{ Family Medicine } & No & $68,040(97.9)$ & $69,821(97.7)$ & $70,651(97.5)$ & $71,990(97.3)$ & $280,502(97.6)$ & \multirow[t]{3}{*}{$<0.001$} \\
\hline & Yes & $1,492(2.1)$ & $1,652(2.3)$ & $1,783(2.5)$ & $1,964(2.7)$ & $6,891(2.4)$ & \\
\hline & Total & $69,532(100)$ & $71,473(100)$ & $72,434(100)$ & $73,954(100)$ & $287,393(100)$ & \\
\hline \multirow[t]{3}{*}{ General Practice } & No & $4,148(96.5)$ & $3,981(95.9)$ & $3,759(95.7)$ & $3,624(95.2)$ & $15,512(95.8)$ & \multirow[t]{3}{*}{0.049} \\
\hline & Yes & $152(3.5)$ & $170(4.1)$ & $169(4.3)$ & $181(4.8)$ & $672(4.2)$ & \\
\hline & Total & $4,300(100)$ & $4,151(100)$ & $3,928(100)$ & $3,805(100)$ & $16,184(100)$ & \\
\hline \multirow[t]{3}{*}{ Internal Medicine } & No & $59,028(98.5)$ & $59,771(98.3)$ & $59,586(98.2)$ & $59,506(98.0)$ & $237,891(98.2)$ & \multirow[t]{3}{*}{$<0.001$} \\
\hline & Yes & $886(1.5)$ & $1,026(1.7)$ & $1,116(1.8)$ & $1,227(2.0)$ & $4,255(1.8)$ & \\
\hline & Total & $59,914(100)$ & $60,797(100)$ & $60,702(100)$ & $60,733(100)$ & $242,146(100)$ & \\
\hline \multirow[t]{3}{*}{ Psychiatry } & No & $11,665(90.5)$ & $11,790(89.8)$ & $11,794(89.8)$ & $11,685(89.2)$ & $46,934(89.8)$ & \multirow[t]{3}{*}{0.005} \\
\hline & Yes & $1,219(9.5)$ & $1,343(10.2)$ & $1,341(10.2)$ & $1,415(10.8)$ & $5,318(10.2)$ & \\
\hline & Total & $12,884(100)$ & $13,133(100)$ & $13,135(100)$ & $13,100(100)$ & $52,252(100)$ & \\
\hline
\end{tabular}

